\title{
Study of Intercondylar Foramen of Humerus - Clinical And Radiological Aspect.
}

\author{
Venkatesh gobi Veerappan ${ }^{1}$, BalajiThotakura ${ }^{3}$, Aruna. $S^{4}$, Kannan.G $G^{5}$, \\ Narayanan. $G^{6}$, Balaji. $K^{7}$ \\ Sivaraj Medical colleges, salem \\ Indra Gandhi institute of medical sciences, Pondycherry \\ Chettinad Hospital and Research Institute, Padur \\ Indra Gandhi institute of medical sciences, Pondycherry \\ Sivaraj Homoeopathic Medical college, salem \\ Sivaraj Medical colleges, salem \\ RVS Dental college, Coimbatore
}

\begin{abstract}
A thin bony plate between coronoid fossa and olecranon fossa of humerus is sometimes perforated to form a foramen named as supra trochlear foramen (STF).It was present between two epicondyles also called intercondylar foramen. The Study was conducted in 74 dried humerus specimens from the Department of Anatomy, Sivaraj institute of medical sciences. Among those 39 are of left side; 35 are of right side. Supratrochlear foramen was seen in 14 (19.17\%) bones, 9 were left side and 5 were right side. Mean transverse diameter of STF was 7.94mm and vertical diameter was 6.01.The presence of STF is associated with narrow intramedullary canal. In this study it was observed that the mean diameter of the intramedullary canal was less $(4.48 \mathrm{~mm})$ for the specimens with such foramen, but in the normal humeri it was $6.36 \mathrm{~mm}$. Knowledge of this variation of Supratrochlear foramen in the distal end of humerus is essential in diagnostic orthopaedics, in intramedullary nailing of humerus and STF is a radiolucent area in radiographs and this may be misinterpreted for osteolytic or cystic lesion.
\end{abstract}

\section{Introduction}

A thin plate of bone separating olecranon fossa and coronoid fossa of humerus situated above the trochlea, when perforated produces a foramen known as septal aperture or supratrochlear foramen (STF).

It is situated between the two epicondyles hence known as intercondylar foramen. Since it is situated above the trochlea also called as epitrochlear foramen. The supratrochlear foramen in humerus was first reported by Meckel in 1825. In humans the foramen ranges from 6-60\% in different races. Generally the shapes of supratrochlear foramen are oval, round, triangular and some are with sieve like apertures. Some bones are with translucent septum. Presence of such supratrochlear foramen in the distal end of humerus is due to absorption of translucent septum of the bone. There is a thin plate of bone situated between the olecranon fossa and coronoid fossa of humerus upto 7 years of age after which the bony septum occasionally becomes absorbed to form the supratrochlear foramen. Mechanical interaction of humerus and ulna during articulation influences the formation of septal aperture. The length of olecranon and coronoid process of ulna and the minimum diameter of the trochlea forms an angle from full flexion to full extension. STF is more when the deviation of forearm is more pronounced, especially in females.

STF in the distal end of the humerus is always associated with a narrow intramedullary canal in its lower end. In normal humerus the canal has the diameter of $6-8 \mathrm{~mm}$ but when such variation (STF) present, the intramedullary canal diameter is $<4 \mathrm{~mm}$. Narrowing of canal is more pronounced in the distal end of humerus above the epitrochlear foramen. Measurements of intramedullary canal are important in the treatment of supracondylar fractures and also in intramedullary nailing procedures. So presence of such foramen makes difficult in preoperative planning of fractures in the distal part of humerus. 


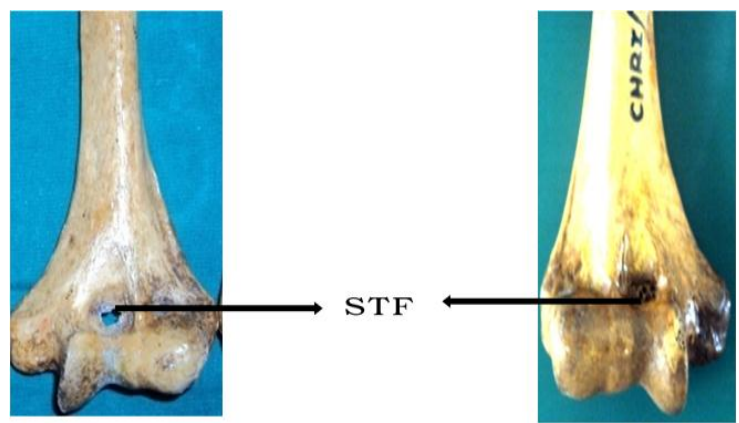

II. Materials And Methods

Study conducted in 74 dried humerus specimens, taken from the Department of Anatomy,Sivaraj institute of medical sciences. Among the 74 specimens, 14 specimens are with STF. The septal apertures are oval, round and triangular in shape, some had translucency of the septum. Then the distance of STF- from medial epicondyle, lateral epicondyle, and from medial flange of trochlea, the diameter of the foramen-vertical and transverse are measured by the digital vernier caliper. Side of variation- Right or Left is also considered. The data are plotted in tabular column.

Radiographs of specimens are taken to observe the translucency of the septum and to measure the diameter of intramedullary canal in 3 levels. 1. Below surgical neck of humerus. 2. Junction between upper $2 / 3^{\text {rd }}$ and lower $1 / 3^{\text {rd }}$ of shaft (just at the commencement of lateral and medial supracondylar ridge). 3 . Above the supratrochlear foramen.

\section{OBSERVATION}

Study includes 74 dried humerus specimens from the Department of Anatomy, Sivarai institute of medical sciences. Among 74 specimens 39 are of left side; 35 are of right side. Supratrochlear foramen was seen in 14 (19.17\%) bones, 9 were left side and 5 were right side.

The shapes of apertures are Oval, Round, Triangular, and Sieve like.

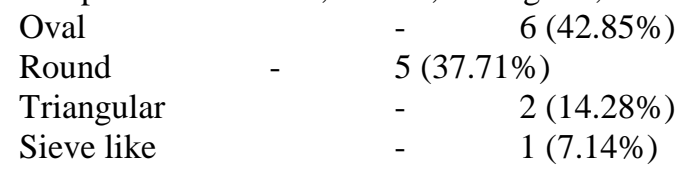

Translucency of septum was noticed in 30 specimens $(50 \%)$.

Radiographs are taken for the humerus with supratrochlear foramen and humerus without the foramen. The area of STF appears radiolucent in lower end of humerus.

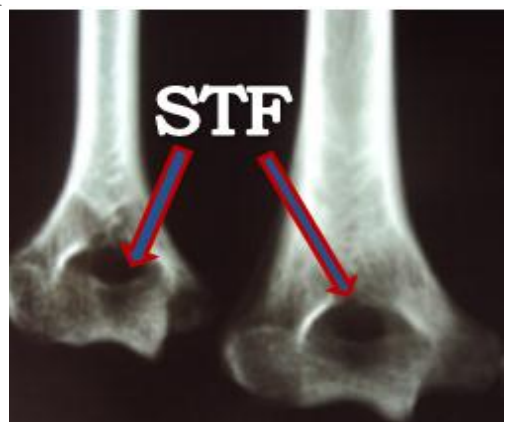

Radiograph of humerus with STF

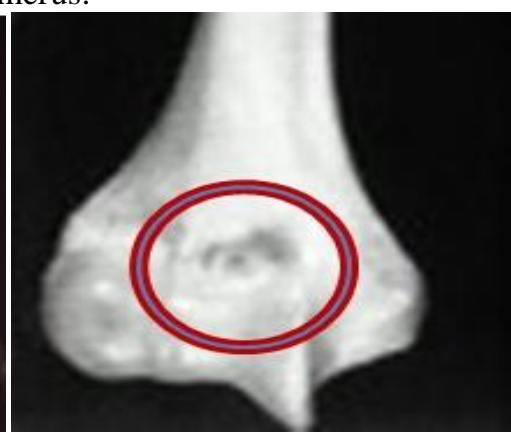

Humerus without STF

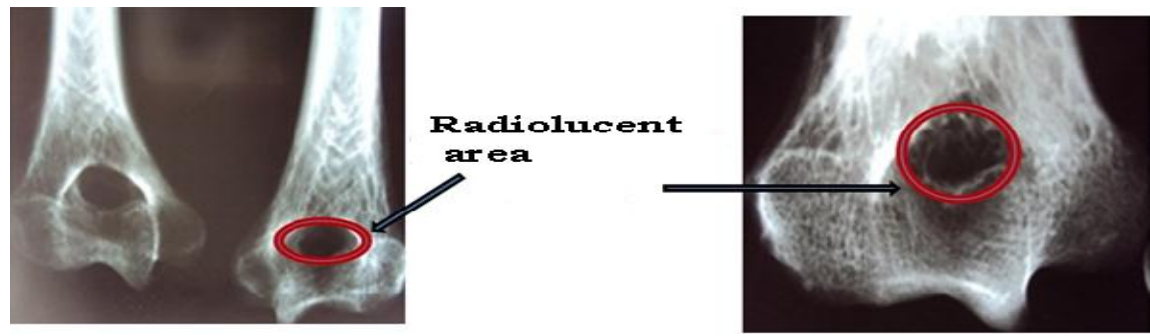

Showing the radiolucency of STF

Mean and S.D of transverse and vertical diameters of STF Diameter Mean and S.D $\mathbf{P}$ - value 
Study Of Intercondylar Foramen Of Humerus - Clinical And Radiological Aspect.

\begin{tabular}{|c|c|c|c|c|}
\hline $\begin{array}{c}\text { Transverse diameter of oval, round } \\
\text { and triangular STF }\end{array}$ & Combined mean & Right & Left & \\
\cline { 2 - 4 } & $7.94 \pm 1.19$ & $8.30 \pm 1.07$ & $7.53 \pm 1.28$ & \multirow{2}{*}{$0.0002 *$} \\
\hline $\begin{array}{c}\text { Vertical diameter of oval, round } \\
\text { and triangular STF }\end{array}$ & $6.01 \pm 1.49$ & $4.09 \pm 1.13$ & $5.35 \pm 1.60$ & \\
\hline
\end{tabular}

* P- value is less than the level of significance (0.05). So the value is extremely statistically significant.

Measurements of intramedullary canal were taken in radiographs in 3 levels;

Mean diameter of intramedullary canal of specimens with Supratrochlear foramen.

\begin{tabular}{|l|l|}
\hline Below the surgical neck & $4.52 \mathrm{~mm}$ \\
\hline $\begin{array}{l}\text { Junction between upper } 2 / 3^{\text {rd }} \text { and lower } 1 / 3^{\text {rd }} \text { of } \\
\text { of shaft }\end{array}$ & $4.87 \mathrm{~mm}$ \\
\hline Above the STF & $4.07 \mathrm{~mm}$ \\
\hline
\end{tabular}

(Specimens with STF)

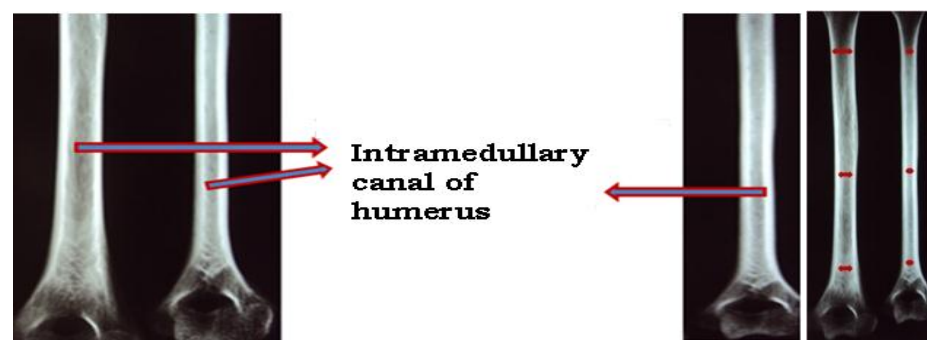

(Measuring diameter of intramedullary canal in-3-levels)

Mean diameter of intramedullary canal of the specimens without STF

\begin{tabular}{|l|l|}
\hline Below the surgical neck & $6.02 \mathrm{~mm}$ \\
\hline Junction between upper $2 / 3^{\text {rd }}$ and lower $1 / 3^{\text {rd }}$ of shaft & $6.44 \mathrm{~mm}$ \\
\hline Above the coronoid fossa & $6.64 \mathrm{~mm}$ \\
\hline
\end{tabular}

Combined mean diameter of intramedullary canal $=\mathbf{6 . 3 6} \mathbf{~ m m}$.

(Specimens without STF)

\section{Discussion}

The anatomical and radiological knowledge of the presence of STF is beneficial for orthopaedic surgeons and radiologist. In the present study incidence of STF found in 14\% of the specimens. In past studies incidence noted as 28\% (Suruchi singal and Vani rao 2007) and 26\% (Anupama mahajan 2011). The incidence of STF in Indian population ranges from 14\% - 28\%. In the present study majority (42.85\%) of septal aperture was oval in shape, this coincides with the past studies of Soubhagya R.nayak 2009 and Suruchi singal and Vani rao 2007. Next to oval, round shape being common, in present study it was $37.71 \%$. Translucency of the septum was observed in $50 \%$ of specimens, in past study it was stated as $56.7 \%$ (Soubhagya R. nayak 2009).

Due to high incidence of STF in the Indian population it requires special attention during intramedullary humeral nailing procedures in the distal portion of humerus, because the presence of STF is associated with narrow intramedullary canal. In the present study we observed the mean diameter of the medullary canal was less $(4.48 \mathrm{~mm})$ for the specimens with such foramen, but in the normal humeri it was 6.36 $\mathrm{mm}$.

Common fracture in the distal end of humerus is supracondylar fracture which accounts for $75 \%$ of all injuries especially in paediatric age group. Usual mechanism of injury is by hyperextension load on the elbow from falling on an outstretched arm. The distal fragment displaces posteriorly in more than $95 \%$ of fractures. Supracondylar fractures are classified into 3 types (Type1- non displaced, Type 2 - angulated with moderate disruption, Type 3- completely displaced, angulated and malrotated). In type 1 fractures closed reduction will give good progress, in type 2 fractures closed reduction and percutaneous pinning procedure can be performed. But in type 3 fractures open reduction is performed (Raymond T. Morrissy and Stuart. L. Weinstein 2006).

Different procedures are encountered in the route of pin entry while treating supracondylar fractures of humerus. The presence of STF in the lower end of humerus makes it more difficult to plan out such procedures 
preoperatively (Fuat akpinar 2003). The entry point of intramedullary nailing for the supracondylar fractures are by retrograde procedure from the distal end.

When the entry point is shifted away from this area due to reduction in the diameter it is hardly possible for the nail to pass through the medulla distally. In treatment of supracondylar fractures open reduction is done by two crossed kirschner wires (Louis Solomon, David. J Warwick, and Selvadurai nayagam 2001). In humenus withSTFantegrade intramedullary nailing procedure can be performed instead of retrograde procedure.

In the present study the position of STF is located near to the medial epicondyle, it coincides with the past study of Soubhagya $\boldsymbol{R}$. nayak 2009. The mean distance of the foramen from medial epicondyle is 23.84 $\mathrm{mm}$ and mean distance from lateral epicondyle is $24.06 \mathrm{~mm}$.

In humeral shaft fractures straight round nails with maximum diameter were used through the distal end and pushed out through the proximal end. It was determined through the radiographic findings. So in humerus with narrow medullary cavity the entry point is encountered as stress point, where normal diameter pin could not be inserted. For which $4 \mathrm{~mm}$ diameter Steinman pin could be inserted. The best point for nail insertion (entry point) appears to be a point anteromedial to greater tubercle (Fuat akpinar 2003).

In plain radiograph supratrochlear foramen appears as a radiolucent area hence can be mistaken for osteolytic or cystic lesion. So presence of the foramen should be kept in mind during any orthopaedic, surgical and diagnostic procedures.

\section{Conclusion}

- Knowledge of this variation of Supratrochlear foramen in the distal end of humerus is essential in diagnostic orthopaedics, because STF is an area which is radiolucent in radiographs and this may be misinterpreted for osteolytic or cystic lesion during radiological examination.

- Knowledge of vertical and transverse diameters of STF,serve in orthopaedic surgeries in an effective way.

- Orthopaedic surgeons should be aware of such variation to make preoperative planning to choose ideal nailing procedure in case of distal humeral fractures due to difficulty in performing normal retrograde intramedullary nailing.

\section{References}

[1]. Akabori E. Septal apertures in the humerus in Japanese, Ainu and Koreans. American Journal of Physical Anthropology. 1934; 18:395-400

[2]. Anupama mahajan. Supratrochlear foramen, study in north Indians. Professional Medical Journal. March 2011; 18(1):128-132.

[3]. Benfer RA, Mckern TW. The correlation of bone robusity with the perforation of the coronoid, olecranon septum in the humerus of man. American Journal of Physical Anthropology. 1966; 24:247-252.

[4]. Fuat akpinar. Amophometricstudyonthehumenusfor intramedullary fixation. Tohoku Journal of experimental medicine. 2003; 19:35-42.

[5]. Hardlika. A. The humerus septal apertures. Anthropologie. 1932; X: 34-96.

[6]. Hirsh SI. Osteochondritis of dissecans of the supratrochlear septum. Journal of bone and joint surgery.1927; 27:12-24.

[7]. Lamb DS. The olecranon perforation. American anthropologist. 1890; 3:159-174.

[8]. Langley- Hobbs.S.J, M.Straw. An anatomical study with relevance to external fixator and intramedullary pin placement- Vetinary comp. Orthopaedics Traumatology. 2004; 18:1-6.

[9]. Louis Solomon, David.J Warwick and Selvadurai nayagam. Apley’s system of orthopaedics and fractures. Fracture and joint injuries. $8^{\text {th }}$ edition, Newyork, Oxford University press Inc., 2001; 596.

[10]. Mall. The incidence of perforation of olecranon fossa in the humerus among Indians. Eastern anthropologist. 1927; 33:105-110.

[11]. Meckel JH. A note on the septal apertures in the humerus of central

[12]. Indians. Eastern anthropologist. 1825; 33:270-284.

[13]. Raymond T. Morrissy and Stuart. L. Weinstein. Lovell and winter's Paediatric orthopaedics. Management of Fractures. $6^{\text {th }}$ edition, Philadelphia, Lippincott Williams Wilkins. 2006; 2: 1449.

[14]. Soubhagya R. Nayak. Supratrochlear foramen of the humerus- An anatomico radiological study with clinical implications. Upsala Journal of medical sciences. 2009; 114: 90-94.

[15]. Suruchi Singhal and Vani rao. Supratrochlear foramen of humerus. Anatomical Science international. 2007; 82:105-107.

[16]. Zait Ender OZKAN. Macro Anatomical investigations on the Hedgehog Skeleton Erinaceus europaeus. Turkish Journal of Vet. Animal Sciences. 2002; 28: 271-274. 